Article

\title{
The Microstructure and Mechanical Properties of Cu-20Ni-20Mn Alloy Fabricated by a Compact Preparation Process
}

\author{
Rui Wang ${ }^{1,2}$, Yilei Fu ${ }^{1,2}$, Guoliang Xie ${ }^{3, *}$, Zifan Hao ${ }^{3}$, Shuai Zhang ${ }^{1,2}$ and Xinhua Liu ${ }^{1,2, *}$ \\ 1 Key Laboratory for Advanced Materials Processing of Ministry of Education, Institute of Advanced \\ Materials and Technology, University of Science and Technology Beijing, Beijing 100083, China; \\ s20181359@xs.ustb.edu.cn (R.W.); s20191347@xs.ustb.edu.cn (Y.F.); s20181391@xs.ustb.edu.cn (S.Z.) \\ 2 Beijing Laboratory of Metallic Materials and Processing for Modern Transportation, University of Science \\ and Technology Beijing, Beijing 100083, China \\ 3 State Key Laboratory for Advanced Metals and Materials, University of Science and Technology Beijing, \\ No. 30, Xueyuan Road, Beijing 100083, China; s20181172@xs.ustb.edu.cn \\ * Correspondence: leon_xq@126.com (G.X.); liuxinhua@ustb.edu.cn (X.L.)
}

Received: 27 October 2020; Accepted: 15 November 2020; Published: 18 November 2020

\begin{abstract}
A novel compact preparation process has been developed to produce a $\mathrm{Cu}-20 \mathrm{Ni}-20 \mathrm{Mn}$ alloy. This process involves heating-cooling combined mould (HCCM) continuous casting, a solution treatment at $800{ }^{\circ} \mathrm{C}$, rolling at room temperature and a final ageing step at $450{ }^{\circ} \mathrm{C}$. This process eliminates two hot deformation processes, namely, hot forging and hot rolling, greatly improving production efficiency and reducing production costs compared with the traditional preparation process. The alloy fabricated by this process was found to have excellent mechanical properties. Additionally, the formation of precipitated phases during the ageing step is accelerated by this new process. The hardness of the samples reaches $476 \mathrm{HV}$ after ageing for $10 \mathrm{~h}$. Stable, ordered precipitates of $\mathrm{Ni}_{3} \mathrm{Mn}\left(\mathrm{L1}_{2}\right.$ phase $)$ are observed in the rolled specimen, and the orientation relationship between the copper matrix and ordered $\mathrm{Ni}_{3} \mathrm{Mn}$ phase $\left(\mathrm{L1}_{2}\right.$ phase) is $[200]_{\mathrm{Cu}} / /[010]_{\mathrm{Ni3Mn}}$ and $[011]_{\mathrm{Cu}} / /[011]_{\mathrm{Ni3Mn}}$. Precipitation strengthening is the main reason for the increase of strength of the sample during the ageing process. The mechanical properties and ageing precipitation process of the alloy are affected by the rolling process. The precipitation rate of the rolled sample is greatly increased during the ageing process, leading to a larger amount of precipitates.
\end{abstract}

Keywords: $\mathrm{Cu}-20 \mathrm{Ni}-20 \mathrm{Mn}$ alloy; compact preparation process; mechanical properties; microstructure evolution; combined ageing process

\section{Introduction}

High-strength elastic copper alloys have been widely used in many fields and applications, such as the aerospace field and in petrochemical electronic equipment, due to their excellent properties, namely, their high strength, elasticity, good thermal conductivity, stress relaxation resistance, excellent corrosion resistance and wear resistance [1-4]. The $\mathrm{Cu}$-Be alloy is considered as an ideal elastic material for applications because it exhibits comprehensive properties that are better than most other copper alloys [5]. However, the production and application of $\mathrm{Cu}$-Be alloys are severely restricted [6,7] due to their need for harsh processing conditions and high production cost. In addition, beryllium oxide and compounds produced in the melting and processing processes are extremely harmful to the human body and environment.

$\mathrm{Cu}-20 \mathrm{Ni}-20 \mathrm{Mn}$ alloy can be used to replace beryllium copper in some areas. $\mathrm{Cu}-20 \mathrm{Ni}-20 \mathrm{Mn}$ alloy have a higher strength and elastic modulus than $\mathrm{Cu}$-Be alloys, along with being very stable at 
high temperatures [8-10]. In addition, this alloy is expected to have excellent application potential in the aerospace, mechanical and chemical fields because of its excellent combustion resistance under oxygen-rich conditions [11]. However, the traditional preparation process includes vacuum casting, hot forging, hot rolling, cold rolling and ageing. Thus, the complexity and high production cost of this traditional preparation process limit the development and application of $\mathrm{Cu}-20 \mathrm{Ni}-20 \mathrm{Mn}$ alloy [12]. This paper proposed a compact process consisting of HCCM continuous casting [13], a solution treatment, cold rolling, and a final ageing step for producing the $\mathrm{Cu}-20 \mathrm{Ni}-20 \mathrm{Mn}$ alloy. The two thermal deformation steps of hot forging and hot rolling, which cannot be omitted in the traditional process, are omitted in this new process. The difficulty of alloy preparation and the production cost are greatly reduced by using this new process, which is conducive to the production and application of $\mathrm{Cu}-20 \mathrm{Ni}-20 \mathrm{Mn}$ alloy.

In this paper, the microstructure and mechanical property evolutions of the $\mathrm{Cu}-20 \mathrm{Ni}-20 \mathrm{Mn}$ alloy produced by this new compact preparation process were investigated, and research on the precipitation process of the $\mathrm{Cu}-20 \mathrm{Ni}-20 \mathrm{Mn}$ alloy was carried out by conducting a series of ageing precipitation tests of specimens rolled at room temperature. The phase transformation sequence during the ageing process is observed by XRD, SEM and TEM techniques. The influence of the rolling deformation on the structure and properties of $\mathrm{Cu}-20 \mathrm{Ni}-20 \mathrm{Mn}$ alloy is analysed. Finally, the strengthening mechanisms that correspond to precipitation behaviours are discussed to provide a theoretical direction for the optimization of this alloy.

\section{Experimental}

\subsection{Material Preparation}

The $\mathrm{Cu}-20 \mathrm{Ni}-20 \mathrm{Mn}$ (mass fraction, \%) alloy was prepared using pure $\mathrm{Cu}, \mathrm{CuNi} 20$ master alloy and CuMn22 master alloy by HCCM continuous casting technology. Figure 1 shows a schematic of the principles of HCCM continuous casting technology.

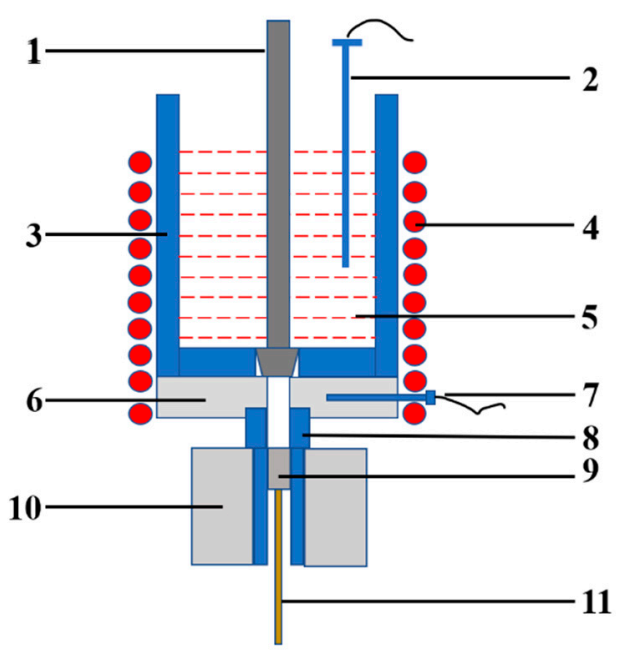

Figure 1. Principle schematic of the HCCM continuous casting technology: 1-graphite stopper, 2, 7-thermocouples, 3-graphite crucible, 4-temperature measuring device, 5-alloy solution, 6-graphite thermal type, 8-graphite mold, 9-dummy bar head, 10-crystallizer, 11—tow bar.

The main feature of the HCCM continuous casting is that the mold is composed of a heating section and a cooling section. The mold heating section is heated by induction coils and the heating temperature is higher than the melting point of the alloy. A forced cooling is performed at the cooling section with a water-cooling copper sleeve. The processing parameters used in the present work were listed as follows: melting and holding temperature $1250{ }^{\circ} \mathrm{C}$, cooling water flow rate $600 \mathrm{~L} / \mathrm{h}$, drawing speed $60 \mathrm{~mm} / \mathrm{min}$. The shape of the casting depends on the shape of the mold and the mold can be 
designed according to the needs to obtain samples of different shapes. The alloy prepared by HCCM continuous casting technology could obtain excellent performance after combined ageing treatment. The combined ageing processing parameters used in the present work were listed as follows: solution treatment at $800{ }^{\circ} \mathrm{C}$ for $1 \mathrm{~h}$, rolling at room temperature with $75 \%, 85 \%$ or $95 \%$ reduction, and final ageing at $450{ }^{\circ} \mathrm{C}$ for different time.

\subsection{Mechanical Properties}

Hardness tests were conducted on a HXD-1000TM/LCD Vicker's hardness tester (Shanghai optical instrument factory, Shanghai, China), with a holding time of $15 \mathrm{~s}$ and a load of $3 \mathrm{~kg}$. The tests corresponding to each condition were repeated at least five times to minimize experimental error.

\subsection{Microstructure Observations and Analysis}

The samples for SEM were first ground, polished and etched in a mixed solution containing $10 \mathrm{~g}$ $\mathrm{FeCl}_{3}+30 \mathrm{~mL} \mathrm{HCl}+120 \mathrm{~mL} \mathrm{C}_{2} \mathrm{H}_{5} \mathrm{OH}$. The specimens for the TEM observations were prepared by a focused ion beam (FIB) with a size of 30-60 nm, which was beneficial for observing by TEM. The microstructures of the samples were observed by scanning electron microscopy (SEM, JEOL-7900 field emission scanning electron microscope, JEOL, Tokyo, Japan) and transmission electron microscopy (TEM, JEM2100 transmission electron microscope, JEOL, Tokyo, Japan).

The specimens for $X$-ray diffraction, with dimensions of $15 \mathrm{~mm} \times 25 \mathrm{~mm} \times 0.3 \mathrm{~mm}$, were ground with 1500 grade water-proof abrasive paper. The experiments were carried out using $X$-ray diffraction (XRD, D8 Advance X-ray diffractometer Bruker, Billerica, MA, USA) with a CuK $\alpha$ radiation source at an accelerating voltage of $40 \mathrm{kV}$, a current of $40 \mathrm{~mA}$ and a continuous scanning rate of $4^{\circ} / \mathrm{min}$.

\section{Results}

\subsection{Variation of the Hardness of the Samples Treated with Different Process}

The variations in the hardness of the solid solution specimens treated with different processes are shown in Figure 2. The hardness of the solid solution specimen is $125 \mathrm{HV}$. There is no significant change in the hardness of the solid solution specimen at the early stage of ageing. The hardness of the solid solution specimen increases rapidly after ageing for $2 \mathrm{~h}$, with its value reaching up to $400 \mathrm{HV}$ after ageing for $24 \mathrm{~h}$. The hardness of the solid solution specimens after ageing for $24 \mathrm{~h}$ is approximately the same.
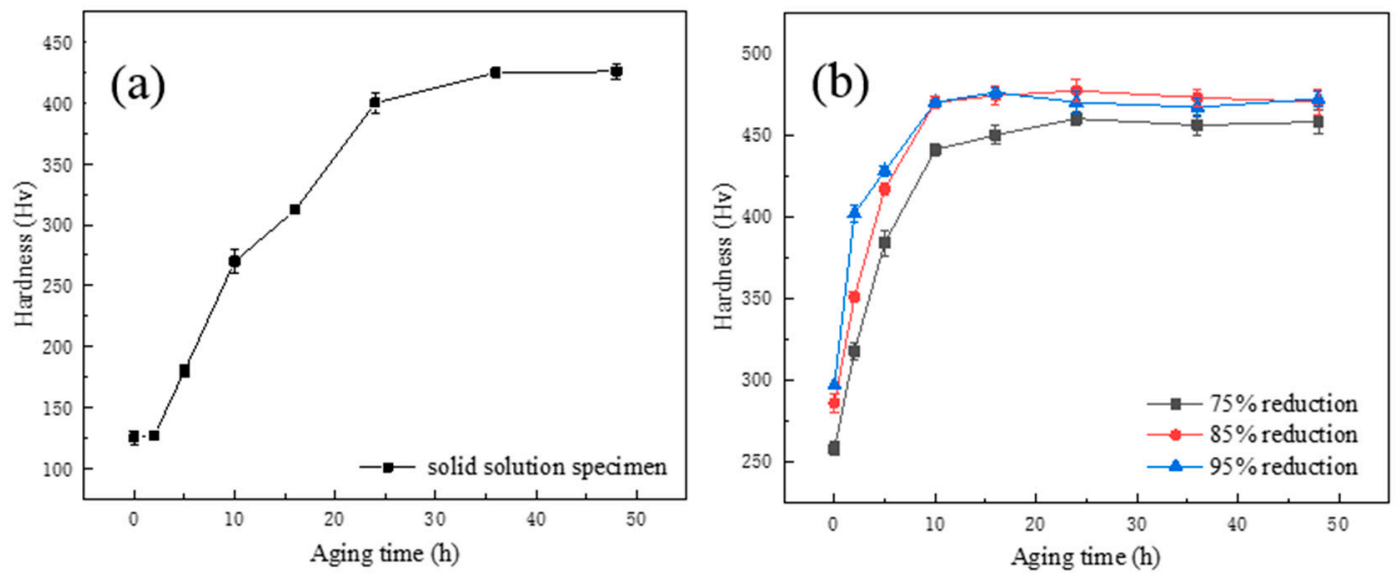

Figure 2. Variation of hardness of the specimens during aging process, (a) the variation of hardness of solid solution specimen, (b) the variation of hardness of specimen treated with different reduction.

The rolling process is beneficial for increasing the hardness of specimens before and after ageing. The hardness values of rolled specimens with 75, 85, and 95\% reduction are 258, 286, and $297 \mathrm{HV}$, 
respectively. The hardness evolutions of the specimens rolled with different reductions during the ageing process are approximately the same. The hardness values of the rolled specimens increase rapidly at the early stage of ageing. The hardness values of the specimens after ageing for $10 \mathrm{~h}$ are approximately the same. Notably, the hardness of the specimen rolled with a $95 \%$ reduction reaches a hardness of $476 \mathrm{HV}$ after ageing for $10 \mathrm{~h}$. The hardness of the specimen fabricated by traditional preparation process is $487 \mathrm{HV}$ in previous study [14]. The hardness of the specimen fabricated by novel compact process is approximately the same as the hardness of the specimen fabricated by traditional preparation process.

These results indicate that the rolling process is beneficial for increasing the hardness of a specimen. Furthermore, the hardness of a sample is affected by the reduction during rolling. The hardness of a sample increases with an increase in the reduction value. The evolution of hardness during the ageing process is also influenced by the rolling process. The precipitation rate during the ageing process of the sample becomes faster through the effect of cold deformation. Therefore, the time required to reach the peak value of strength during the ageing process of the rolled samples is greatly reduced compared with that of the solid solution sample because there is an incubation period during the ageing of solid solution samples. However, the incubation period is not found during the ageing process of the rolled samples. In addition, the hardness of the rolled samples at their peak ageing states are higher than that of the solid solution state. These changes in hardness are caused by the evolution of the microstructure, which will be analysed in the following discussion section.

\subsection{Microstructure of the Sample Treated with Different Rolling Process}

The microstructures of specimens treated with different rolling processes are demonstrated in the SEM micrographs shown in Figure 3. A large number of columnar grains are found in specimens prepared by HCCM continuous casting technology, as shown in Figure 3a. Moreover, these columnar crystals are not eliminated by the solution treatment. Therefore, a large amount of columnar crystal structures are still observed in the solution-treated sample, as shown in Figure $3 \mathrm{~b}$. The microstructure of the sample changes through cold deformation. The microstructure of the rolled specimen is found to transform from columnar grains to slender fibrous structures, as seen in Figure 3c-e.

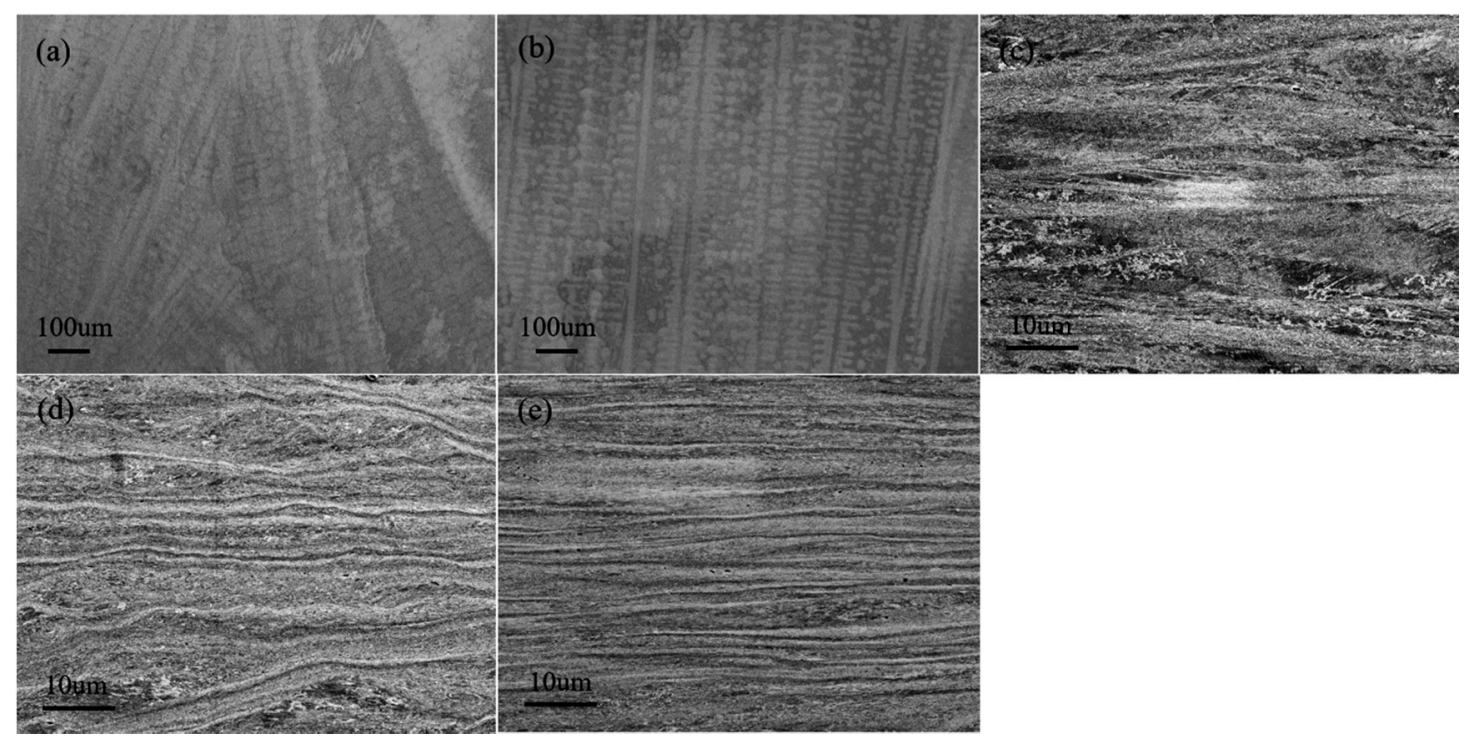

Figure 3. SEM micrographs of specimens treated with different rolling processes: (a) as-cast specimen, (b) solid solution specimen, (c) rolled specimen with a 75\% reduction, (d) rolled specimen with an $85 \%$ reduction, and (e) rolled specimen with a $95 \%$ reduction.

The grain size will be affected by the reduction during rolling. The grain size becomes very fine after cold deformation with a 95\% reduction, as shown in Figure 3e. Thus, the mechanical properties 
and ageing precipitation process of the alloy will be affected by cold deformation, which will be analysed in the following discussion section.

\subsection{Microstructure Evolution of the Rolled Sample during Aging Process}

The TEM micrographs and corresponding SAED patterns of the rolled specimens aged at $450{ }^{\circ} \mathrm{C}$ for 2, 10 or $48 \mathrm{~h}$ are shown in Figure 4 . Two kinds of precipitates can be found in the sample, as seen in Figure 4a. One kind is a very small precipitate of approximately $5-10 \mathrm{~nm}$, and the other is approximately 15-20 nm. The diffraction spots of the $\mathrm{Ni}_{3} \mathrm{Mn}$ phase ( $\mathrm{L}_{2}$ phase) are found in Figure $4 \mathrm{~b}$, which have previously not been found in a $\mathrm{Cu}-20 \mathrm{Ni}-20 \mathrm{Mn}$ alloy. The orientation relationship between the copper matrix and ordered $\mathrm{Ni}_{3} \mathrm{Mn}$ phase $\left(\mathrm{L}_{2}\right.$ phase) is $(200)_{\mathrm{Cu}} / /(010)_{\mathrm{Ni} 3 \mathrm{Mn}}$ and $[011] \mathrm{Cu} / /[011] \mathrm{Ni} 3 \mathrm{Mn}$. A large amount of precipitates can also be found in the rolled specimens aged for $10 \mathrm{~h}$, as seen in Figure $4 \mathrm{c}$. The orientation relationship between the copper matrix and ordered $\mathrm{Ni}_{3} \mathrm{Mn}$ phase ( $\mathrm{L}_{2}$ phase) is $(020)_{\mathrm{Cu}} / /(010)_{\mathrm{Ni3Mn}}$ and [001]Cu//[001]Ni3Mn. Furthermore, the number of precipitates observed in the sample after $48 \mathrm{~h}$ of ageing increase, and the sizes of the precipitates observed in the $48 \mathrm{~h}$-aged sample are approximately the same. In addition, many interference fringes are observed in the rolled specimen aged for $48 \mathrm{~h}$, as shown in Figure $4 \mathrm{e}$. The reason for these interference fringes is due to the abundance of small, coherent precipitates that are produced from the matrix.

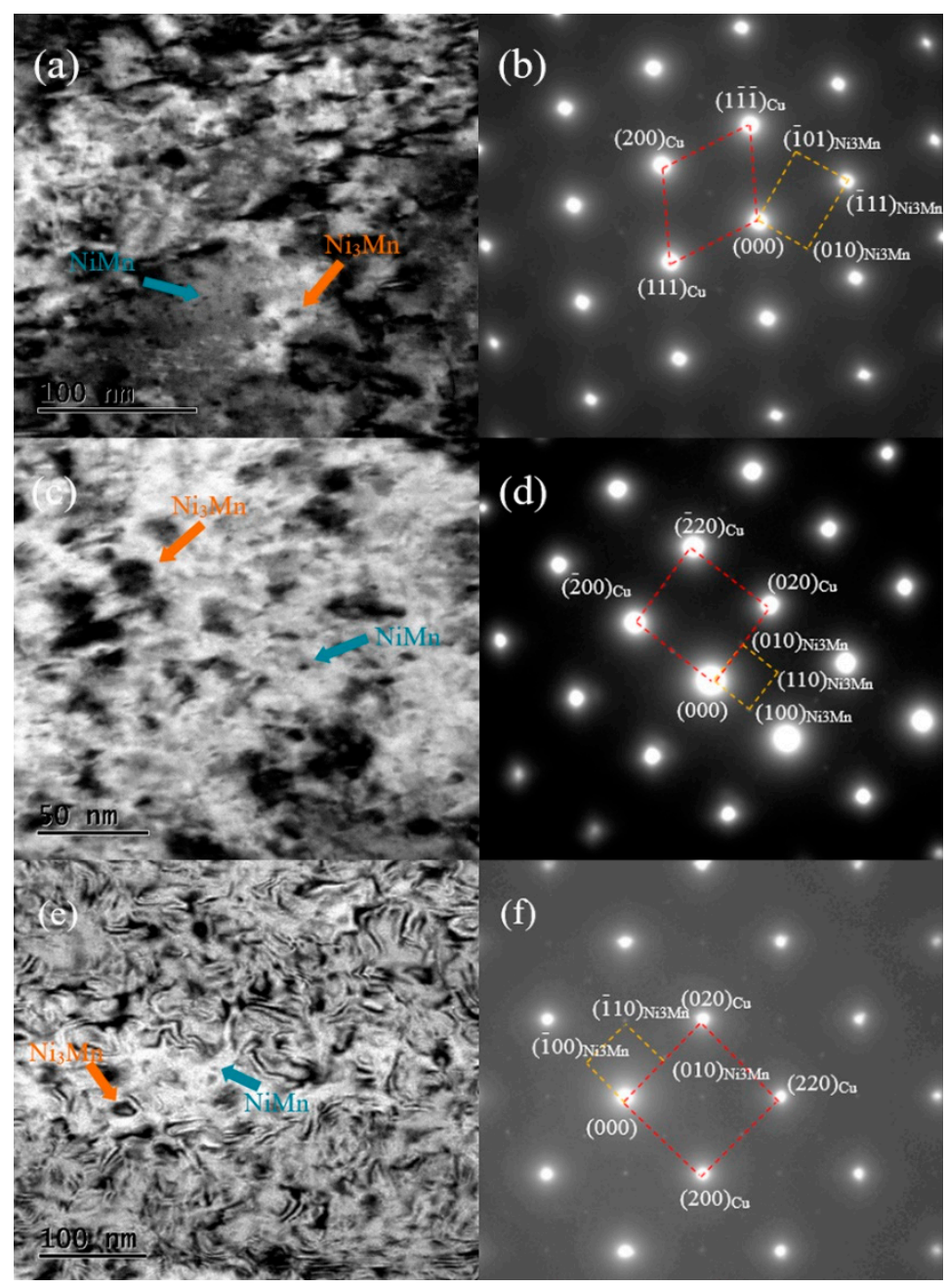

Figure 4. TEM micrographs and SAED patterns of the rolled specimens aged at $450{ }^{\circ} \mathrm{C}$ for 2,10 or $48 \mathrm{~h}$ : (a) TEM micrograph and (b) [011]Cu SAED pattern of the rolled specimen aged for $2 \mathrm{~h}$, (c) TEM micrograph and (d) [001]Cu SAED pattern of the rolled specimen aged for $10 \mathrm{~h}$, and (e) TEM micrograph and (f) [001]Cu SAED pattern of the rolled specimen aged for $48 \mathrm{~h}$. 
The $\mathrm{Ni}_{3} \mathrm{Mn}$ phases are still found in the $48 \mathrm{~h}$-aged sample, which is confirmed by the diffraction spots of the ordered $\mathrm{Ni}_{3} \mathrm{Mn}$ phase ( $\mathrm{L}_{2}$ phase) found in the SAED pattern (Figure $4 \mathrm{f}$ ). It is difficult to determine whether the NiMn phase is also present in the specimen by the SAED pattern because the position of the partial diffraction spots of the $\mathrm{Ni}_{3} \mathrm{Mn}$ phase coincides with the diffraction spots of the NiMn phase. The existence of NiMn is discussed later in the XRD analysis. This is the first study to show the $\mathrm{Ni}_{3} \mathrm{Mn}$ phase in an aged $\mathrm{Cu}-20 \mathrm{Ni}-20 \mathrm{Mn}$ alloy. The generation of these $\mathrm{Ni}_{3} \mathrm{Mn}$ phases and their impact on the alloy properties are discussed in the following discussion section.

Figure 5 shows the $\mathrm{XRD}$ patterns of the rolled specimens aged at $450{ }^{\circ} \mathrm{C}$ for different times in two different $2 \theta$ ranges. The (220) peaks of the rolled specimen gradually widen as the ageing time increases, and the peaks of the ordered NiMn phase appear in the vicinity of the matrix peak in the XRD patterns of the rolled specimens aged for a long period of time, as shown in Figure 5. The XRD patterns confirm the existence of the NiMn phase during the ageing process in the rolled samples, indicating that there are two types of precipitated phases ( $\mathrm{NiMn}$ and $\mathrm{Ni}_{3} \mathrm{Mn}$ ) in the specimens after ageing for $2 \mathrm{~h}$. These results are in good agreement with the TEM results.
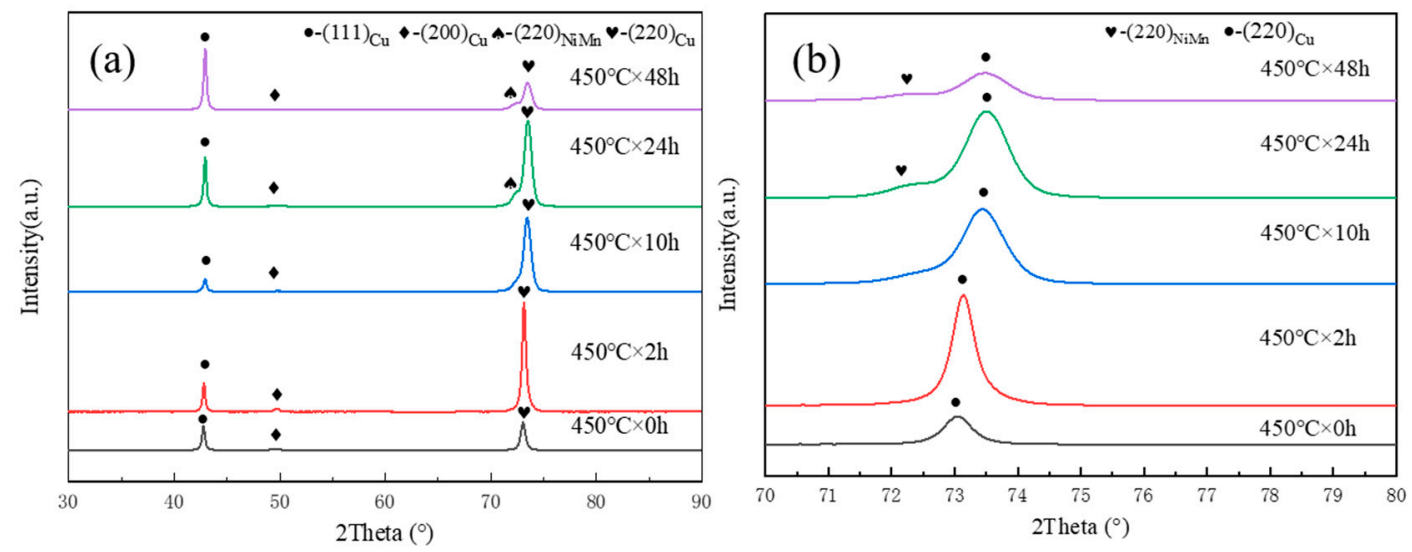

Figure 5. The XRD patterns of the rolled specimens aged at $450{ }^{\circ} \mathrm{C}$ for different time in different $2 \theta$ ranges, (a) $30-90^{\circ}$, (b) $70-80^{\circ}$.

\section{Discussion}

\subsection{Strengthening Mechanism of the Alloy during the Ageing Process}

It can be seen from the previous results that the hardness of the alloy increases greatly through the ageing process. The hardness of the rolled specimen reached $476 \mathrm{HV}$ after ageing for $24 \mathrm{~h}$, while its hardness before the ageing process was only $297 \mathrm{HV}$. The evolution of the hardness is caused by the evolution of the microstructure. According to the results above, the microstructural evolution of the rolled specimens during the ageing process can be identified. The precipitates consist of two phases (NiMn and $\mathrm{Ni}_{3} \mathrm{Mn}$ ) that rapidly precipitate at the early stage of ageing. The NiMn phase is considered the main precipitation phase during the ageing process [8,15], with $\mathrm{L} 1_{0}$ structure. The structure of the $\mathrm{Ni}_{3} \mathrm{Mn}$ phase with face-centred cubic ( $\mathrm{L1}_{2}$ structure) structure is found in the aged $\mathrm{Cu}-20 \mathrm{Ni}-20 \mathrm{Mn}$ alloy, which is firstly reported in this alloy. The $\mathrm{Ni}_{3} \mathrm{Mn}$ phase is also an ordered precipitated phase, with the size of $15-20 \mathrm{~nm}$, as seen in Figure 6, which is larger than that of the NiMn phase. $\mathrm{The}^{\mathrm{Ni}} 3 \mathrm{Mn}$ phase is considered to be transformed from the unstable NiMn phase during the ageing process based on the observations of the alloy during the entire aging process, suggesting that the $\mathrm{Ni}_{3} \mathrm{Mn}$ phase is more stable than the NiMn phase. More precipitates appear as the ageing time increases. In addition, the size of the precipitates do not change significantly after ageing for a long time, which may be the reason why the specimen still exhibits a high strength after ageing for a long time. 


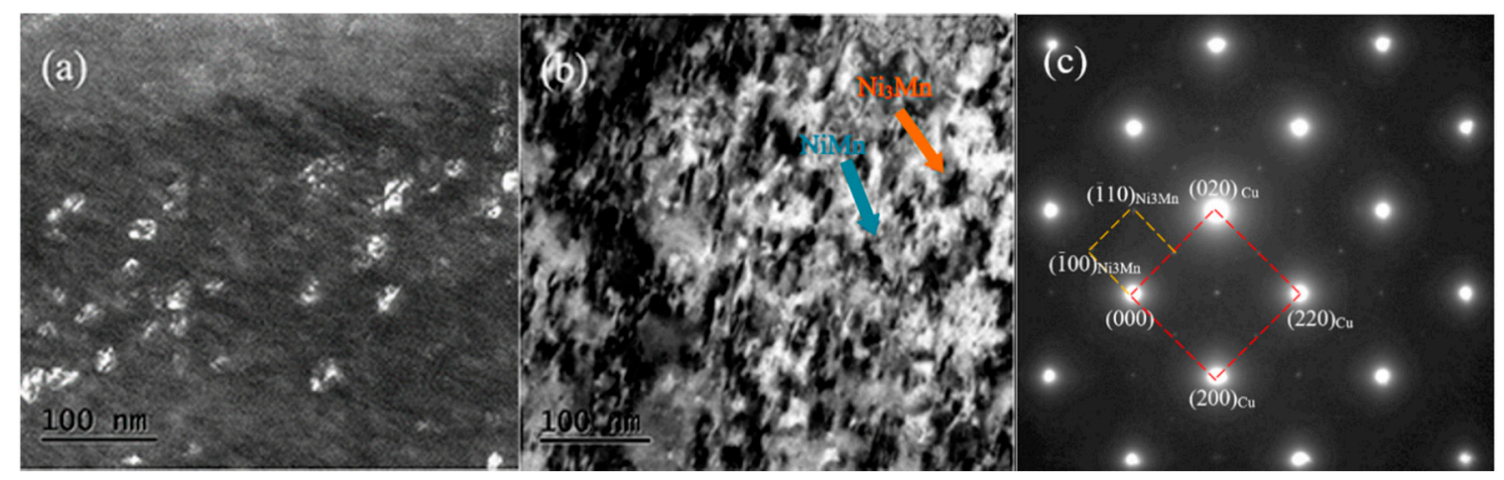

Figure 6. TEM micrographs of the rolled specimens aged at $450{ }^{\circ} \mathrm{C}$ for $48 \mathrm{~h}$ : (a) the dark field image of the $\mathrm{Ni}_{3} \mathrm{Mn}$ phase, (b) the bright field image, (c) [001]Cu SAED pattern of the specimen.

The hardness of an alloy is considered to be the combined effect of the superposition of multiple strengthening mechanisms, i.e., the solid solution strengthening, grain boundary strengthening, precipitation strengthening and work hardening mechanisms [16-18]. Grain boundary strengthening can be ignored since grain boundary strengthening contributes little during the ageing process. Solid solution strengthening can be expressed [19] as:

$$
\Delta \sigma_{s S}=M G_{0}\left[\left(\beta \frac{\alpha_{1}-\alpha_{0}}{\alpha_{0}}\right)^{2}+\left(2 \frac{G_{1}-G_{0}}{G_{1}+G_{0}}\right)^{2}\right]^{\frac{2}{3}} c^{\frac{2}{3}}
$$

where $M$ is the Taylor factor, $G_{0}$ is the shear modulus of the copper matrix, $\alpha_{0}$ is the lattice constant of the copper matrix, $G_{1}$ is the shear modulus of the solute, $\alpha_{1}$ is the lattice constant of the solute and $\mathrm{c}$ is the concentration of the solute in the alloys.

It can be seen from Equation (1) that solid solution strengthening is closely related to the content of solute. Consequently, the effect of solid solution strengthening will decrease if the solute content decreases. The large amount of precipitates that form during the ageing process continuously decreases the content of $\mathrm{Ni}$ and $\mathrm{Mn}$ in the matrix. Therefore, the contribution of solid solution strength should decrease during the ageing process.

The mechanism of work hardening can be expressed [20] as:

$$
\Delta \sigma_{\rho}=M \alpha G \mathrm{~b} \rho^{\frac{1}{2}}
$$

where $M$ is the Taylor factor, $\alpha=0.2$ is the constant in copper alloys, $G$ is the shear modulus of the matrix, $\mathrm{b}$ is the Burgers vector, and $\rho$ is the dislocation density.

The effect of work hardening is closely related to the dislocation density according to Equation (2). The contribution of work hardening will decrease with decreasing dislocation density. The dislocation density decreases during the ageing process because of the recovery and recrystallization that occurs in the matrix and the generation of discontinuous precipitates. Therefore, the contribution of work hardening decreases during the ageing process.

Therefore, it is suggested that the increase in hardness is mainly contributed by precipitation strengthening, since the hardness of the alloy further increases during the ageing process and the other strengthening effects decrease according to the discussions above.

Precipitation strengthening is mainly caused by hindering the movement of dislocations, the mechanisms of which are mainly divided into two types, namely, the Orowan mechanism (bypassing) and the cutting mechanism [21,22]. The sizes of NiMn phases are approximately 5-10 nm. Therefore, the cutting mechanism is probably considered the main strengthening mechanism of the small NiMn precipitates, since the sizes of NiMn phases are quite small (approximately 5-10 nm). Compared with 
the NiMn phase, the $\mathrm{Ni}_{3} \mathrm{Mn}$ phase is larger in size; thus, the sample will be strengthened by the $\mathrm{Ni}_{3} \mathrm{Mn}$ precipitates in the form of dislocation bypassing.

\subsection{Effect of Rolling Process on Microstructure and Properties of Cu-20Ni-20Mn Alloys}

The mechanical properties and ageing precipitation process of the alloy will be affected by cold deformation, which has been observed in the previous results. The hardness of the rolled specimen is greatly improved compared with that of the solid solution sample. The microstructure of the rolled specimen is found to transform from a columnar crystal structure to a slender fibrous structure, which is beneficial for obtaining many fine grains. In addition, the dislocation density is also greatly increased by the rolling process. Grain boundary strengthening and work hardening are the main reasons for the increase in hardness. Therefore, the precipitation process of the specimen during ageing is also influenced by cold deformation.

The precipitation rate during the ageing process of the sample increases through the effect of cold deformation. The time required to reach the peak strength during the ageing process of the rolled samples is greatly reduced compared with that of the solid solution samples. The incubation period is not found during the ageing process of the rolled sample, while it can be found during the ageing process of the solid solution sample. In addition, the hardness of the rolled sample at the peak ageing state is higher than that of the solid solution state. These changes in hardness are caused by the evolution of the microstructure. According to the results above, the deformation storage energy of the sample increases after the rolling process, which is beneficial for increasing the precipitation rate. In addition, many fine grains and a high dislocation density are obtained by the rolling process, which is beneficial for obtaining more precipitated phases because the number of nucleation sites increase during the ageing process. According to the discussion above, the mechanical properties of the alloy are improved by decreasing the grain size of the sample and increasing the dislocation density by rolling deformation. In addition, the precipitation rate of the rolled sample is greatly increased during the ageing process; thus, more precipitates can be obtained during the ageing process of the rolled sample.

\section{Conclusions}

A new compact preparation process involving heating-cooling combined mould (HCCM) continuous casting, a solution treatment at $800^{\circ} \mathrm{C}$, rolling at room temperature, and a final ageing step at $450^{\circ} \mathrm{C}$ was developed to produce a $\mathrm{Cu}-20 \mathrm{Ni}-20 \mathrm{Mn}$ alloy. Compared with the traditional preparation process, the proposed process eliminated two hot deformation processes, namely, hot forging and hot rolling, which greatly improved the production efficiency and reduced production costs. The alloy fabricated by this new process was found to have excellent mechanical properties, and the hardness of the samples reached $476 \mathrm{HV}$. The following conclusions can be drawn from the results presented in this paper:

(1) Two types of precipitates, i.e., $\mathrm{NiMn}$ and $\mathrm{Ni}_{3} \mathrm{Mn}$, could be observed in the aged sample. The structure of the $\mathrm{Ni}_{3} \mathrm{Mn}$ phase is face-centred cubic ( $\mathrm{L}_{2}$ structure), with the orientation relationship between the copper matrix and ordered $\mathrm{Ni}_{3} \mathrm{Mn}$ phase ( $\mathrm{L1}_{2}$ phase) is $\left.{ }^{(200)}\right)_{\mathrm{Cu}} / /(010)_{\mathrm{Ni3Mn}}$ and [011]Cu//[011]Ni3Mn.

(2) Precipitation strengthening is the main strengthening mechanism of the ageing process. The cutting mechanism is the main strengthening mechanism of the small NiMn precipitates. $\mathrm{The} \mathrm{Ni}_{3} \mathrm{Mn}$ phase is larger in size, suggesting that the sample will be strengthened by the $\mathrm{Ni}_{3} \mathrm{Mn}$ precipitates in the form of dislocation bypassing.

(3) The ageing precipitation process and mechanical properties of the alloys are affected by the rolling process. The precipitation rate of the rolled sample is greatly increased during the ageing process. The time required to reach the peak ageing during the ageing process of rolled samples is greatly reduced compared with solid solution samples. The incubation period is not found during the 
ageing process of the rolled sample, which could be found during the ageing process of the solid solution sample. In addition, more precipitates could be obtained during the ageing process of the rolled sample, which led to the hardness of the rolled sample in the peak ageing state being higher than that of the solid solution state.

Author Contributions: Conceptualization, R.W., Y.F. and G.X.; data curation, R.W. and S.Z.; funding acquisition, X.L. and G.X.; investigation, R.W., G.X. and X.L.; methodology, R.W., Y.F. and Z.H.; project administration, X.L. and G.X.; writing-original draft, R.W.; writing-review and editing, R.W. and G.X. All authors have read and agreed to the published version of the manuscript.

Funding: This research was supported by the National Natural Science Foundation for Distinguished Young Scholars of China (grant numbers 51925401); The Funds for Creative Research Groups of China (grant no. 51921001); the National Ten Thousand Talents programme of China; the Fundamental Research Funds for the Central Universities (grant nos. FRF-TP-19-020B1Z); Youth Foundation of National Natural Science Foundation China (grant numbers 52001020).

Conflicts of Interest: The authors declare no conflict of interest.

\section{References}

1. Yuan, S.J.; Pehkonen, S.O. Surface characterization and corrosion behavior of 70/30 Cu-Ni alloy in pristine and sulfide-containing simulated seawater. Corros. Sci. 2007, 49, 1276-1304. [CrossRef]

2. Wu, Y.; Li, Y.; Lu, J.; Tan, S.; Jiang, F.; Sun, J. Correlations between microstructures and properties of Cu-Ni-Si-Cr alloy. Mater. Sci. Eng. A 2018, 731, 403-412. [CrossRef]

3. Shen, L.; Li, Z.; Zhang, Z.; Dong, Q.; Xiao, Z.; Lei, Q.; Qiu, W. Effects of silicon and thermomechanical process on microstructure and properties of $\mathrm{Cu}-10 \mathrm{Ni}-3 \mathrm{Al}-0.8 \mathrm{Si}$ alloy. Mater. Des. 2014, 62, 265-270. [CrossRef]

4. Liu, J.Z.; Chen, J.H.; Hu, T. The crystallographic and morphological evolution of the strengthening precipitates in Cu-Ni-Si alloys. Acta Mater. 2013, 61, 1210-1219.

5. Zhang, H.; Jiang, Y.; Xie, J.; Li, Y.; Yue, L. Precipitation behavior, microstructure and properties of aged Cu-1.7 wt\% Be alloy. J. Alloy Compd. 2019, 733, 1121-1130. [CrossRef]

6. Xie, G.; Wang, Q.; Mi, X.; Xiong, B.; Peng, L. The precipitation behavior and strengthening of a Cu-2.0wt $\% \mathrm{Be}$ alloy. Mater. Sci. Eng. A 2012, 558, 326-330.

7. Zhou, Y.J.; Song, K.X.; Xing, J.D.; Zhang, Y.M. Precipitation behavior and properties of aged Cu-0.23Be-0.84Co alloy. J. Alloy Compd. 2016, 658, 920-930. [CrossRef]

8. Xie, W.B.; Wang, Q.S.; Mi, X.J.; Xie, G.L.; Liu, D.M.; Gao, X.C.; Yang, L.I. Microstructure evolution and properties of Cu-20Ni-20Mn alloy during aging process. Trans. Nonferrous Met. Soc. China 2015, 25, 3247-3251. [CrossRef]

9. Pan, Q.H. The Cu-20Ni-20Mn alloy with high elasticity. Chin. J. Nonferrous Met. 1996, 6, 91-95.

10. Cai, W.; Wu, Y.; Yin, J.Z.; Wang, G.; Yang, S.L.; Wang, C.X. Effect of Ti on the Structure and Properties of Cu-15Ni-10Mn Alloy As-Cast Smelted at Atmosphere. In Advanced Materials Research; Trans Tech Publications Ltd.: Stafa-Zurich, Switzerland, 2014; Volume 887, pp. 362-365.

11. Shao, L.; Xie, G.; Liu, X.; Wu, Y.; Yu, J.; Wang, Y. Combustion behaviour and mechanism of a Cu-Ni-Mn alloy in an oxygen enriched atmosphere. Corros. Sci. 2020, 163, 108253. [CrossRef]

12. Xu, S.Y.; Li, Y.L.; Cai, Z.H.; Ding, H. The current situation and prospect for high-strength and high-elasticity copper alloy. J. Mater. Metall. 2018, 17, 64-69.

13. Wang, J.; Lei, Y.; Liu, X.H.; Xie, G.L.; Jiang, Y.Q.; Zhang, S. Microstructure and properties of Cu-Al-laminated composites fabricated via formation of a horizontal continuous casting composite. Chin. J. Eng. 2020, 42, 216-224.

14. Pan, Q.H. Heat treatment process of $\mathrm{Cu}-\mathrm{Ni}-\mathrm{Mn}$ alloy. Heat Treat. Met. 1985, 3, 43-48.

15. Wang, D.M.; Pan, Q.H. Study on Aging Phase Transformation of Cu-Ni-Mn Alloy. Rare Met. Mater. Eng. 1986, 06, 44-48.

16. Starink, M.J.; Wang, S.C. A model for the yield strength of overaged Al-Zn-Mg-Cu alloys. Acta Mater. 2003, 51, 5131-5150. [CrossRef]

17. Zhang, X.; Godfrey, A.; Huang, X.; Hansen, N.; Liu, Q. Microstructure and strengthening mechanisms in cold-drawn pearlitic steel wire. Acta Mater. 2011, 59, 3422-3430. [CrossRef] 
18. Chihiro, W.; Satoshi, T.; Ryoichi, M. Effects of Small Addition of Ti on Strength and Microstructure of a Cu-Ni-Si Alloy. Metall. Mater. Trans. A 2015, 46, 2469-2475.

19. Labusch, R. A Statistical Theory of Solid Solution Hardening. Phys. Status Solidi 1970, 41, 659-669. [CrossRef]

20. Balogh, L.; Ungár, T.; Zhao, Y.; Zhu, Y.T.; Horita, Z.; Xu, C.; Langdon, T.G. Influence of stacking-fault energy on microstructural characteristics of ultrafine-grain copper and copper-zinc alloys. Acta Mater. 2008, 46, 471-473. [CrossRef]

21. Mabuchi, M.; Higashi, K. Strengthening mechanisms of Mg-Si alloys. Acta Mater. 1996, 44, 4611-4618. [CrossRef]

22. Lee, J.; Jung, J.Y.; Lee, E.S.; Park, W.J.; Ahn, S.; Kim, N.J. Microstructure and properties of titanium boride dispersed $\mathrm{Cu}$ alloys fabricated by spray forming. Mater. Sci. Eng. 2000, 277, 274-283. [CrossRef]

Publisher's Note: MDPI stays neutral with regard to jurisdictional claims in published maps and institutional affiliations.

(C) 2020 by the authors. Licensee MDPI, Basel, Switzerland. This article is an open access article distributed under the terms and conditions of the Creative Commons Attribution (CC BY) license (http://creativecommons.org/licenses/by/4.0/). 